\title{
Silent Gastroesophageal Reflux Disease
}

\author{
Ching-Liang Lu \\ Division of Gastroenterology, Department of Medicine, Taipei Veterans General Hospital, and Institute of Brain Science, National Yang-Ming \\ University, Taipei, Taiwan
}

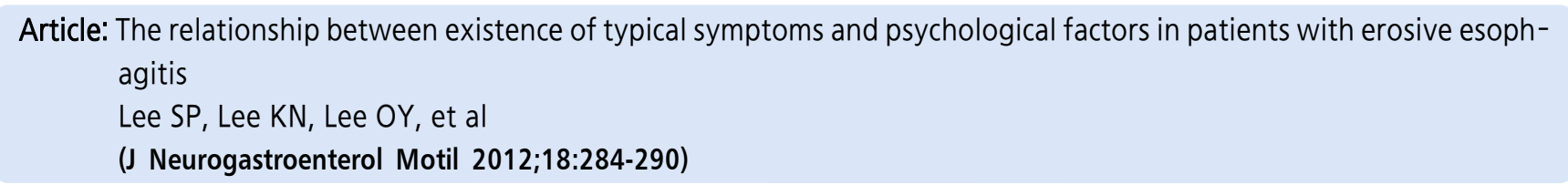

Gastroesophageal reflux disease (GERD) is defined as the presence of acid-reflux-related symptoms, or esophageal mucosal damage, caused by the reflux of gastric contents into the esophagus. ${ }^{1}$ The diagnosis of GERD can therefore be easily made by patients' complaint of typical (heartburn and regurgitation) and/or atypical acid-reflux-related symptoms (chest pain, globus, chronic cough and asthma etc). On the other hand, the GERD diagnosis can also be obtained through esophagogastroduodenoscopy (EGD) by visible esophageal mucosal break. Recently, non-erosive gastroesophageal reflux disease (NERD) has been defined as the presence of acid-reflux-related symptoms, but without esophageal mucosal breaks. ${ }^{2}$ Symptomatic GERD is costly, brings a significant negative impact on health-related quality of life, and even is linked with esophageal adenocarcinoma. ${ }^{3-5}$ GERD had been considered as an uncommon disease in Asia. However, in recent years, a rising prevalence of both GERD and reflux esophagitis has been reported in various Asian countries. Most of the GERD cases reported in Asia are of the non-erosive type, and complications such as Barrett's esophagus and esophageal adenocarcinoma still rare in this part of the world. ${ }^{6,7}$ Fass and Dickman ${ }^{8}$ has first described the concept of so called 'silent GERD,' which referred to the presence of esophageal mucosal injury (ie, erosion, ulceration or even Barrett's esophagus) visible in EGD, but without typical or atypical GERD symptoms. Actually, a population-based study from Sweden already showed that up to $36.8 \%$ of patients with erosive esophagitis had no symptoms in 2004 . $^{9}$ Several studies from Asia by investigating the subjects receiving routine EGD check-up have described the characteristics of the silent GERD. ${ }^{10-15}$ These Asian studies showed the prevalence of the silent GERD ranged from $11.6 \%$ to $45.3 \%$ in patients with EGD-proven erosive esophagitis. Factors leading to asymptomatic esophagitis have been evaluated in these studies and with inconsistent results. For example, both Nozu and Wang identified male sex as a predictive factor for silent GERD. ${ }^{11,12}$ Cho et $\mathrm{al}^{13}$ found older age ( $>60$ years old) and male sex were predictive of asymptomatic esophagitis. Smoking and lower body mass index (BMI) were shown to be the predictive factors for silent GERD in a Japan study, ${ }^{11}$ while Wang from Taiwan found that a higher BMI predicted absence of symptoms in erosive esophagitis. ${ }^{12}$ In another survey

Received: May 31, 2012 Revised: June 22, 2012 Accepted: July 1, 2012

(c) This is an Open Access article distributed under the terms of the Creative Commons Attribution Non-Commercial License (http://creativecommons. org/licenses/by-nc/3.0) which permits unrestricted non-commercial use, distribution, and reproduction in any medium, provided the original work is properly cited.

*Correspondence: Ching-Liang Lu, MD

Division of Gastroenterology, Department of Medicine, Taipei Veterans General Hospital, No. 201, Sec. 2, Shih-Pai Rd., Taipei 11217, Taiwan

Financial support: None.

Tel: +886-2-28712111 (ext. 3385), Fax: +886-2-28739318, E-mail: cllu@vghtpe.gov.tw

Conflicts of interest: None. 
from Taiwan, neither age nor BMI was associated with asymptomatic GERD. ${ }^{14}$ But, male sex, hiatus hernia and positivity for Helicobacter pylori infection were predictive of silent GERD. A recent study from Japan showed the patients with asymptomatic esophagitis were older and had more frequent use of calcium channel blockers than the symptomatic ones. In this issue, Lee et $\mathrm{al}^{15}$ from Korea conducted a small scaled study by enrolling 29 symptomatic and 26 asymptomatic patients with erosive gastritis from routine check-up. The demographic data, atypical GERD symptoms, dyspeptic symptoms and psychological symptoms were compared between the symptomatic and silent GERD patients. Not surprisingly, the authors found that symptomatic GERD patients were more likely to have atypical symptoms, functional dyspepsia symptoms and higher scores on psychological symptoms (somatization, obsessive-compulsiveness and phobic anxiety) than those without. These findings were consistent with the study from Japan showing quality of life was more impaired in symptomatic than asymptomatic patients with reflux esophagitis. ${ }^{14}$ The authors then concluded that psychological status and associated dyspeptic or atypical symptoms should be assessed in GERD patients, especially in refractory cases. ${ }^{15} \mathrm{We}$ fully agreed with the author's suggestion. Actually, the association between psychological factor and GERD symptoms has already been well documented. For example, GERD patients who are chronically anxious and exposed to prolonged stress tend to perceive low intensity esophageal stimuli as painful reflux symptoms. $^{16}$

Beside the psychological issue frequently associated with GERD patients, the unanswered, but still important, question is the clinical implication and long-term prognosis in these silent GERD patients. Whether the treatment is necessary in this group of GERD 'patient' is an open question. To further characterized the natural history of silent esophagitis may be required for resolving this issue. While the majority of the silent GERD patients are of milder form of esophagitis (grade A or B), whether they will evolve into more severe grades (C or D) and even Barrett's esophagus if left untreated is unclear. Even though Barrett's and esophageal adenocarcinoma are still rare in Asian countries, ${ }^{6}$ the data from Western countries suggested that around $25 \%$ of Barrett's esophagus and $40 \%$ of all esophageal adenocarcinomas occurred in patients without, or with only minimal, prior reflux symptoms. ${ }^{5,17}$ Thus, these patients with silent erosive esophagitis may need to be regularly followed up. Furthermore, patients with refractory asthma and chronic cough are sometimes associated with GERD but without typical GERD symptoms. ${ }^{18,19}$ For these patients, the presence of acid reflux may partially contribute to the refractory respiratory symptoms. Protonpump inhibitors may be initiated in this group of patients.

In conclusion, the risk factors and natural history for silent GERD remain unclear. More studies are needed to better characterize and give proper suggestions to this group of 'patients'.

\section{References}

1. Vakil N, van Zanten SV, Kahrilas P, Dent J, Jones R; Global Consensus Group. The Montreal definition and classification of gastroesophageal reflux disease: a global evidence-based consensus. Am J Gastroenterol 2006;101:1900-1920.

2. Fass R, Fennerty MB, Vakil N. Nonerosive reflux disease - current concepts and dilemmas. Am J Gastroenterol 2001;96:303-314.

3. Ronkainen J, Aro P, Storskrubb T, et al. Gastro-oesophageal reflux symptoms and health-related quality of life in the adult general population - the Kalixanda study. Aliment Pharmacol Ther 2006;23: 1725-1733.

4. Lu CL, Lang HC, Chang FY, et al. Social and medical impact, sleep quality and the pharmaceutical costs of heartburn in Taiwan. Aliment Pharmacol Ther 2005;22:739-747.

5. Lagergren J, Bergstrom R, Lindgren A, Nyrén O. Symptomatic gastroesophageal reflux as a risk factor for esophageal adenocarcinoma. N Engl J Med 1999;340:825-831.

6. Ho KY. From GERD to Barrett's esophagus: is the pattern in Asia mirroring that in the West? J Gastroenterol Hepatol 2011;26:816824.

7. Lu CL, Lang HC, Luo JC, et al. Increasing trend of the incidence of esophageal squamous cell carcinoma, but not adenocarcinoma, in Taiwan. Cancer Causes Control 2010;21:269-274

8. Fass R, Dickman R. Clinical consequences of silent gastroesophageal reflux disease. Curr Gastroenterol Rep 2006;8:195-201.

9. Ronkainen J, Aro P, Storskrubb T, et al. High prevalence of gastroesophageal reflux symptoms and esophagitis with or without symptoms in the general adult Swedish population: a Kalixanda study report. Scand J Gastroenterol 2005;40:275-285.

10. Ohara S, Kouzu T, Kawano T, Kusano M. [Nationwide epidemiological survey regarding heartburn and reflux esophagitis in Japanese.] Nihon Shokakibyo Gakkai Zasshi 2005;102:1010-1024. [Japanese]

11. Nozu T, Komiyama H. Clinical characteristics of asymptomatic esophagitis. J Gastroenterol 2008;43:27-31.

12. Wang FW, Tu MS, Chuang HY, Yu HC, Cheng LC, Hsu PI. Erosive esophagitis in asymptomatic subjects: risk factors. Dig Dis Sci 2010;55:1320-1324.

13. Cho JH, Kim MH, Ko GJ, et al. Old age and male sex are associate with increased risk of asymptomatic erosive esophagitis: analysis of data from local health examinations by the Korean National Health Insurance Corporation. J Gastroenterol Hepatol 2011;26:10341038.

14. Wang PC, Hsu CS, Tseng TC, et al. Male sex, hiatus hernia, and Helicobacter pylori infection associated with asymptomatic erosive esophagitis. J Gastroenterol Hepatol 2012;27:586-591. 
15. Lee SP, Lee KN, Lee OY, et al. The relationship between existence of typical symptoms and psychological factors in patients with erosive esophagitis. J Neurogastroenterol Motil 2012;18:284-290.

16. Bradley LA, Richter JE, Pulliam TJ, et al. The relationship between stress and symptoms of gastroesophageal reflux: the influence of physiological factors. Am J Gastroenterol 1993;88:11-19.

17. Gerson LB, Shetler K, Triadafilopoulos G. Prevalence of Barrett's esophagus in asymptomatic individuals. Gastroenterology 2002;123: 461-467.

18. Asano K, Suzuki H. Silent acid reflux and asthma control. N Engl J Med 2009;360:1551-1553.

19. Blondeau K, Dupont L, Mertens V, Tack J, Sifrim D. Improved diagnosis of gastro-oesophageal reflux in patients with unexplained chronic cough. Aliment Pharmacol Ther 2007;25:723-732. 